\title{
CHATTERBOX: Developing and Piloting an Interactive Communication Toolkit for Engaging Families with Dental Services
}

Sucharita Nanjappa* and Ruth Freeman

Dental Health Services Research Unit, University of Dundee, Dundee, Scotland

"Corresponding author: Dr Sucharita Nanjappa, BDS, MSc, PhD, Lecturer in Dental Public Health, Dental Health Services Research Unit, 9th Floor, Dundee Dental Hospital and School, Park Place, Dundee, Scotland DD1 4HN, Tel: +44 (0)1382 381713; E-mail: s.nanjappa@dundee.ac.uk

Received date: October 09, 2014, Accepted date: October 31, 2014, Publication date: November 4, 2014

Copyright: @ 2014 Nanjappa S et al. This is an open-access article distributed under the terms of the Creative Commons Attribution License, which permits unrestricted use, distribution, and reproduction in any medium, provided the original author and source are credited.

\begin{abstract}
Oral health inequalities exist in Scotland and although regular dental attendance contributes to good oral health outcomes, socio-economically deprived families are less likely to attend the dentist even when dental care is provided free of cost. Communication is key to developing good relationships between health care providers and service users, which is influential in ensuring attendance.
\end{abstract}

Aim: To develop a toolkit to facilitate communication between socially excluded parents and Dental Health Support Workers (DHSWs) to aid their dental attendance.

Method: Discussions between public health dentists and service designers resulted in an interactive storyboarding toolkit called CHATTERBOX.

Results: CHATTERBOX is made up of a timeline base, activity cards and appointment postcards. The activity cards are pictorial representations of everyday family activities and of barriers identified by parents as influencing dental attendance. Nine blank cards allow for parents to describe other concerns not already represented. Parents select relevant cards and place them on the timeline to construct a visual narrative of their day. The cards are also used to raise issues relating to dental attendance such as transportation, childcare, social support, previous dental experiences and other dental-related concerns that families may have. The DHSWs use CHATTERBOX to initiate a structured conversation around the populated timeline to identify where, when and why problems occur when attending for dental care. The timeline is photographed and used again in subsequent visits. CHATTERBOX encourages a two-way interaction by opening up dialogue between DHSWs and parents. CHATTERBOX becomes a platform for parents to reflect, identify problems, consider solutions and eventually solve their own problems.

Conclusion: The discussion between players aids the development of confidence and consolidates relationships between DHSWs and families. This improved communication allows the DHSWs to tailor support according to the specific needs of the family, which further improves the family's likelihood of attending for dental care.

Keywords: Communication; Relationship building; Barriers to dental care; Oral health inequalities; Interdisciplinary collaboration

\section{Background}

Communication is the foundation of the treatment alliance between health care professionals and their patients [1]. The treatment alliance is based upon the reality of the care provided by the health professional for the client and permits the client to accept the treatment the health professional is offering through a negotiated pathway. Difficulties emerge in this working relationship when communication is stalled, either by clients being unable to find the words to express their felt needs and/or the health professional being unable to engage with the clients' true needs. The need for a treatment alliance built on a communicative strategy based upon mutual understanding would have the potential to address such relational difficulties. A health care communication package tailored to the specific needs of the client, for instance, would assist in increasing client adherence with health care interventions [2-5].
This is particularly relevant for parents and children residing in areas of high social deprivation, where problems in accessing health care have been associated with communication difficulties, feelings of shame about missed appointments and difficult encounters with health-centre staff [6]. In order to allow parents to speak about their experiences, it is necessary to develop a tool as a communication device to assist engagement. While several communication packages exist [7], what is suggested here is an interactive tool, which through the medium of pictures provides a space for parents to raise concerns $[8,9]$. Access to dental care may be used by way of illustration, to show how the development of an interactive communication aid assisted parents to express their felt needs and facilitated their access to dental services for their children.

\section{Why is access to dental services for children important?}

Poor oral health can negatively impact on oral health-related quality of life, self-esteem and confidence [10]. One of the major contributors to poor oral health is untreated decay of the deciduous dentition, which is the tenth most prevalent condition world-wide [11]. Dental 
decay is preventable by limiting sugar in the diet to $5 \%$ of the daily energy intake [12] and by brushing twice daily with a fluoridated toothpaste [13]. These two evidence-based oral health messages are the advice given to parents when they take their children for dental care. In addition, regular dental attendance also allows for the early detection of disease, which makes preventative interventions such as application of fluoride varnish and fissure sealants possible without the need for more invasive treatments such as fillings or extractions. Therefore, appropriate dental attendance has the potential to improve the child's self-oral health care, oral health-related quality of life and provides the basis for maintenance of oral health behaviours throughout life [14-17].

\section{Childsmile, DAPER and CHATTERBOX}

The Childsmile Programme in Scotland [18], based on proportionate universalism [19], has recognised that oral health inequalities exist, with children from the $20 \%$ most deprived areas having the greatest decay experience and the lowest access to dental care. Thus, the Childsmile Programme through its core nursery and school fluoride tooth brushing programme, its fluoride varnish programme and its dental practice programme has targeted childhood oral health inequality and actively encouraged access to dental care. Recent national oral health surveys have shown significant improvements in Scottish children's oral health. Nevertheless, major disparities remain and parents and their children living in the most deprived communities still continue to suffer from dental decay and experience increased barriers to access dental care [20,21].

The practice component of the Childsmile Programme targets families and their infants and links them with specific Childsmile NHS Dental Practices. Families are assessed by Health Visitors (community nurses) who attend parents and their children within the family home. The Health Visitors determine whether the child is at risk of developing tooth decay and refers the at-risk child and her family to a Dental Health Support Worker (DHSW). The DHSW visits the family, provides oral health advice and assists parents to register and access a Childsmile dental practice. Although registration rates for Scottish pre-school children have improved enormously, with $47 \%$ of $0-2$ year olds currently (24th June 2014) registered with an NHS dentist, this nevertheless falls short of the national target of $55 \%[22,23]$.

In order to explore why parents from areas of high social deprivation miss their children's dental appointments, the DAPER project (Developing an inventory to Assess Parental concerns and Enable child dental Registration) was conceived. The first part of DAPER explored parental felt reasons for non-attendance. Parents revealed that the difficulties they experienced were related to personal and family issues (e.g. mothers feeling depressed, families not feeling settled in their homes, having difficult neighbors and not being happy with where they were living) and service-related factors (e.g. feeling isolated from health services, perceiving the dental surgery as not family friendly, difficulties and financial costs of travelling with young children on public transport) [24].

The second part of DAPER was to use the parents' felt reasons for non-attendances as the basis of a communication tool in which the parents would be encouraged to speak about the difficulties they experienced when accessing dental care. It was envisaged that enabling parents to raise concerns and speak about their worries would facilitate the formation of a treatment alliance and reduce barriers to accessing dental care. The interactive communication tool was named
CHATTERBOX. With its brightly colored cards and drawings CHATTERBOX provided the DHSWs with a communication interface through which parents would find the words to express their concerns. This would permit the DHSWs to facilitate engagement and tailor their support according to the parents' specific needs.

The development of CHATTERBOX and the subsequent field trial were informed by the MRC framework for complex interventions to improve health [25]. In this article we describe the design of CHATTERBOX, followed by a qualitative exploration using direct observation to illustrate how CHATTERBOX was used to engage with marginalized families to promote children's dental attendance.

\section{Designing CHATTERBOX}

Discussions with Duncan of Jordanstone College of Art and Design (DJCAD) led to the development of a toolkit based on interactive storyboarding [26]. The interactive storyboard went through a series of iterations, user testing and stakeholder meetings and resulted in a uniquely designed tool kit called CHATTERBOX. CHATTERBOX consists of a set of bespoke tools: a timeline base, reusable interactive communication cards and appointment postcards (Figure 1). The interactive communication cards are pictorial representations of parents' everyday activities and the factors that they identified as influencing their attendance for dental treatment for their children [24]. The figures themselves may not always have specific meanings, it is the whole exchange between the parent and the DHSW which will allow barriers to be broken, relationships to be built and care to be tailored to specific needs.

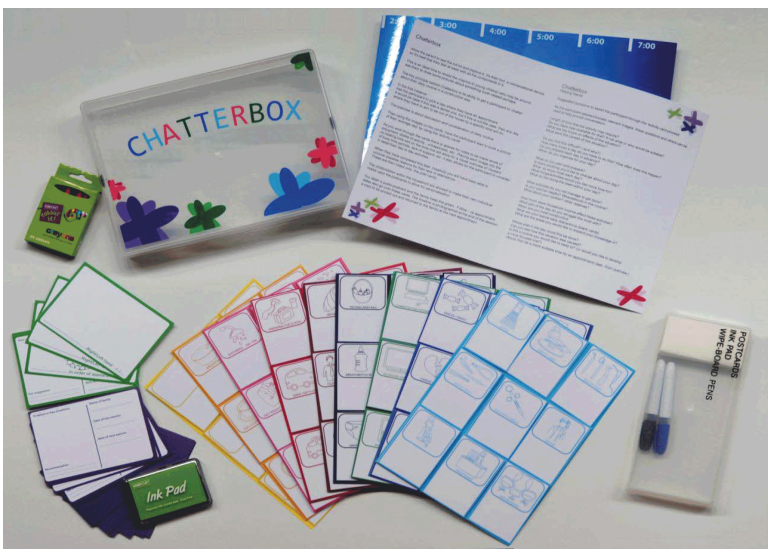

Figure 1: CHATTERBOX.

CHATTERBOX was piloted with three families with young children. Following this pilot, a number of blank cards (to allow parents to describe other concerns) and additional interactive communication cards such as "musical beds" were added. Seventy-two interactive communication cards were separated into categories and colour-coded to simplify selection.

\section{Using CHATTERBOX}

CHATTERBOX is presented to the parent and they are invited to open the box and select relevant interactive communication cards and place them on the timeline base. Parents are encouraged to make comments or notes on the cards using easy wipe markers available in the kit. This organisation of the interactive communication cards, the 
pictures and illustrations in sequence, from morning to night, forms a visual narrative of the family's day. This visualization of daily life provides a communication interface to enable parents to talk about problems and raise concerns about taking their children to the dentist. The problems identified and solutions discussed are transferred onto appointment postcards included in the kit. Each postcard serves as a record and a reminder of the next DHSW appointment to allow further discussion and support parents to find their own solution. The postcards are made unique to each family by having the child's foot/ hand imprinted onto the front of the postcard, acting as an incentive for parents to keep the postcard. The timeline is photographed, printed and used as a platform to aid further discussion at subsequent visits. CHATTERBOX includes a box of crayons and coloring pages for the children.

CHATTERBOX is thus a communication platform to help develop parents' ability to identify their concerns, to consider solutions and eventually to solve their difficulties in accessing care. Using this mutual participation approach improves partnership working and engagement between parents and the DHSWs.

\section{Exploring CHATTERBOX: A Feasibility Study}

\section{Sample}

A purposive sample of nine families who were visited by DHSWs in two Scottish NHS Boards, between June 2012 and July 2013. These families were referred to the Dental Health Support Workers by [i] Health Visitors who risk assessed the families and felt they required assistance with registering their children with a dental practice and by [ii] dental clinics when children failed to attend two or more scheduled appointments.

\section{Data Collection}

Two training workshops in communication skills and using CHATTERBOX were conducted prior to the home visits. The project was approved by The East of Scotland Research Ethics Service (EoSRES) REC 2 (REC Reference No. 12/ES/0037) and NHS R \& D departments (NRSPCC ID: NRS12/GH51). Parents who were willing to participate in the study, after reading the Participant Information Sheet, were requested to sign a consent form. Observation of five home visits by the researcher ( $\mathrm{SN}$ ) permitted an examination of how CHATTERBOX was used with families living in areas of high socioeconomic deprivation.

\section{Results}

\section{Family 1}

Jane was a full time parent who lived in council housing with her four children aged three, six, eight and nine. Jane suffered from depression. Jane was referred to the DHSW because she had missed her children's last dental appointment. Jane used CHATTERBOX to describe a typical school day, which was when she usually scheduled her children's dental appointments. Jane spoke of her depression and how she found it very stressful to manage all four children in the waiting room of the dental practice. Jane said she felt anxious about using public transport and usually got her dad to drive her to her children's appointments. Using CHATTERBOX (Figure 2) Jane identified that the best time for her to take her older children was between 9 a.m. and 10:45 a.m., which was the time that her youngest child was in nursery; although she said that ideally she would prefer to take all four children together. The DHSW conveyed that she was willing to accompany Jane and all four children to the dentist and look after the children in the waiting room while Jane accompanied one child at a time into the surgery. Jane was happy with this suggestion and attended the dental appointment that was made for her children by the DHSW. As planned, Jane was accompanied by the DHSW who remained with the family until all children were examined by the dentist.

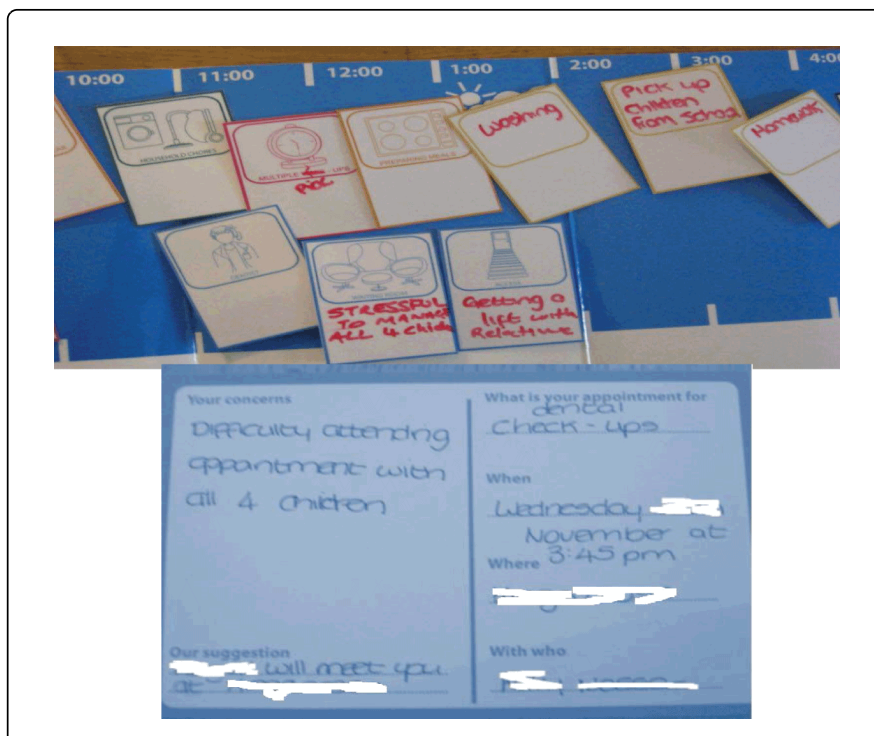

Figure 2: Dental-related concerns identified by Jane and support tailored to the concerns identified.

\section{Family 2}

Norah was a 38 year old full time parent and single mother who lived with her four children, three under the age of ten and one fourteen year old son with learning difficulties, in council housing. Norah was happy to participate in the study when approached by the DHSW. Norah's nine year old daughter Zoe had failed her previous dental appointments. Norah said repeatedly that the "only reason" Zoe failed to attend the dentist was because Norah was forgetful to such a degree that she forgot her own appointments. Norah recognised her forgetfulness so stuck reminders on her refrigerator to help her remember. She spoke of her dental-related concerns such as getting Zoe to brush her teeth at night. Zoe stated that she did not need to brush at night because she was due to get fillings at the dentist anyway. The DHSW spoke to Zoe about the benefits of regular tooth brushing with fluoride toothpaste and reminded Zoe that brushing regularly would stop her needing fillings in the future. When populating the CHATTERBOX timeline Norah spoke about being unable to find full time employment because of the demands of her son Tim who had learning difficulties. Norah mentioned that she was registered at a different dental practice from her children and requested that she be transferred to the same practice as them. The DHSW stated that she would do this for Norah. Zoe picked up the activity cards relating to dental visits and spoke about her previous experiences at the dentist. Zoe selected a picture with dental instruments (Figure 3 ) on it and spoke about her fear of needles, she said that she liked the dentist but 
"got scared" when she went into the surgery and saw the instruments. She also mentioned that although she thought the DHSW was nice, she was quite scared of the fluoride varnishing procedure in School. Following the CHATTERBOX intervention with the DHSW Norah and Zoe kept their next dental appointments.

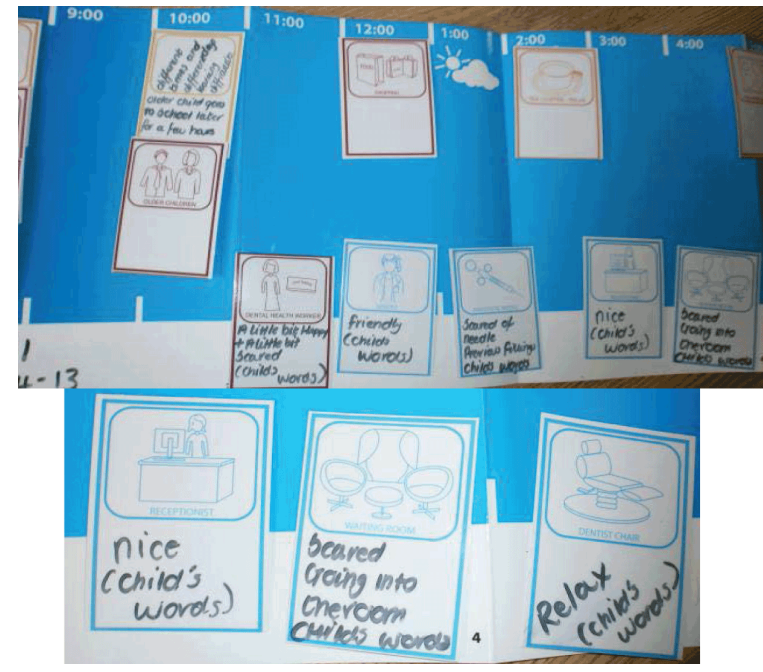

Figure 3: Norah and Zoe's dental related concerns.

\section{Family 3}

Sally was a 29 year old full time parent and single mother who lived in council housing with her four children, two boys and two girls, three under the age of seven. Sally's former partner was physically abusive and was in prison at the time of the intervention. Sally spoke about having a fear of the dentist ever since she experienced severe pain during a treatment visit. Sally had not visited the dentist in many years and as a result felt she had "bad teeth". Sally said she had been very careful not to "pass the fear" onto her children. Sally had failed numerous dental appointments for her children in the past because of her own dental anxiety. Sally was happy to have a chance to talk about this using CHATTERBOX (Figure 4). She was able to identify that a 10 a.m. appointment would suit her best as the children were ready by 9 a.m. for school and there was a 9:30 a.m. bus they could catch that would take them past the dentist. In addition, Sally felt it was easier to take them before school rather that in and out of school or in the evenings, which was her busiest time of the day as she prepared three to four different types of meals. Sally also mentioned that Thursdays were not convenient for her as she usually did her food shopping on Thursdays. A dental appointment was arranged for the children according to Sally's preferences. Following the CHATTERBOX intervention with the DHSW Sally kept her children's next and subsequent dental appointments and always telephoned her DHSW if she missed any appointment.

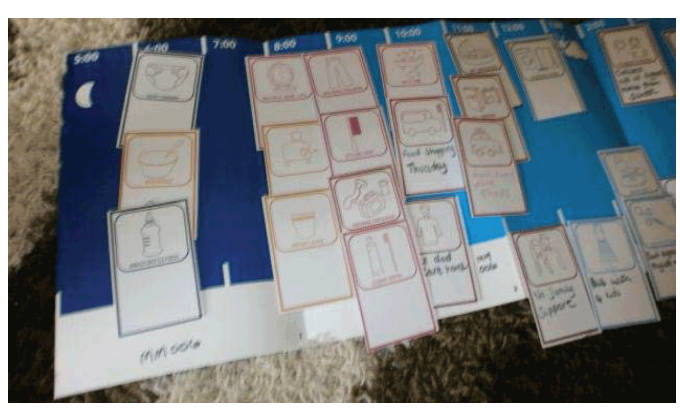

Figure 4: Sally’s populated timeline.

\section{Family 4}

Mary was a single mother with one child aged two years. Mary did not work outside the home and lived in council housing. Mary was getting dressed as the DHSW arrived for a scheduled 11 a.m. appointment. Mary was very pleasant and friendly and invited the DHSW to sit in the lounge while she put away the dishes in her kitchen. Mary was keen to report how hectic her life was and was very happy to talk about her previous day using CHATTERBOX (Figure 5). She used many cards to show how busy she was. Mary's two year old daughter May wanted constant attention in addition to the chaos of two six month old kittens running around the flat. Initially, May was content to use the crayons and colouring sheets included in CHATTERBOX but soon grew tired and wanted to play with the activity cards. When Mary scolded May the little girl started crying and was sent to her room, but soon returned. Mary seemed to have a hectic schedule, however, a closer look at the timeline allowed Mary to comment that her time could be better managed. Mary suggested that she use a 24 hour time line as she was up all night because of noisy neighbours and wanted to show that on the timeline. Mary also suggested that cards such as ironing, disciplining children, unexpected phone calls/ visitors, tidying the house and looking after pets were included in the CHATTERBOX kit. When the DHSW asked Mary if she preferred to make an appointment with a dental practice close to where she lived, Mary said she had a bad experience with one of the local dentists and didn't want to return there. When asked if she wanted to visit a different practice in the same area, Mary replied that she had heard that the dentist that the DHSW was talking about did lots of unnecessary treatment. Mary then mentioned wanting to be seen at the dental school, as she was sure they would never do any unnecessary treatment there. Mary then got up to get her child ready to go to the park, as the weather was good at the time. Mary was happy for the DHSW to visit her for a follow up appointment. When the DHSW tried to contact Mary for a follow up visit she found that Mary had moved out of the area with her daughter. They could not be contacted as no forwarding address had been provided. 


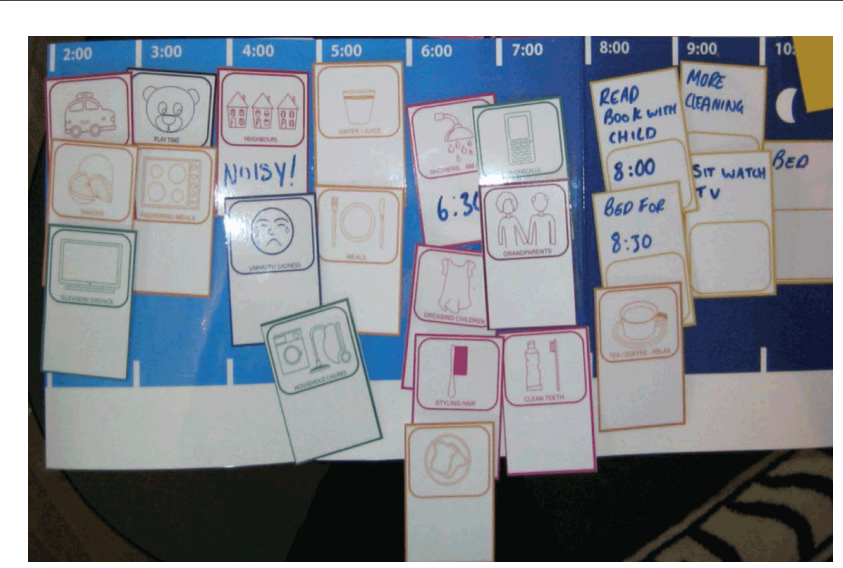

Figure 5: Mary's timeline showing a typical day for Mary.

\section{Family 5}

Meg was a 26 year old mother with a two year old son. She worked part time and lived with her partner (child's father) in a privately rented property. The DHSW, who described Meg as very accommodating, had previously visited $\mathrm{Meg}$ and arranged an appointment for her with the local dentist, whose practice was only a few minutes walk from Meg's house. The DHSW had called the practice, to arrange the appointment, from Meg's house. Meg failed to take her son Tom for his dental appointment. The DHSW was informed by the practice that the family had missed their appointment. The DHSW made a second appointment and notified Meg by letter and text. Meg failed to take Tom along for this appointment. The DHSW was then told by the practice that they were not happy to register the family if they failed to attend again. The DHSW decided to visit the family and use CHATTERBOX before making another appointment on their behalf. When the DHSW visited the house Meg was very welcoming and immediately apologized for failing Tom's appointments. She said she had to get her boiler fixed so missed the initial appointment time, but she did go to the practice in the afternoon and found that it was closed. Meg also said she did not receive the letter or text informing her of Tom's second appointment. Meg mentioned, many times, that she felt bad that she hadn't taken Tom to the dentist as yet. When the DHSW introduced her to CHATTERBOX Meg readily agreed to participate. With the DHSW Meg quickly mapped out her day on the CHATTERBOX timeline (Figure 6). Meg identified a time in the afternoon when she was usually out with Tom visiting her mother, as appropriate for a dental appointment. She then said she would call the practice herself and make an appointment for the next day. Meg agreed to a follow up visit by the DHSW and asked the DHSW to call and arrange a time for it. Following this visit, Meg could not be contacted by the DHSW and missed Tom's dental appointment three times. She was referred back to the Health Visitor for follow up.

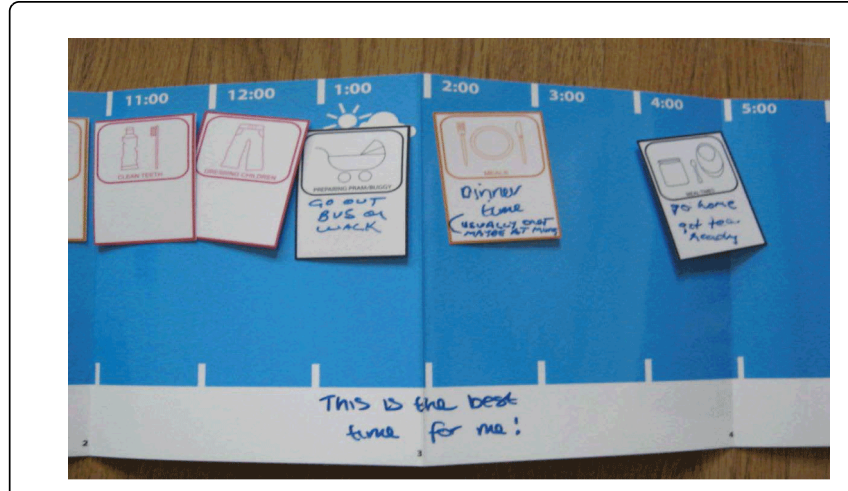

Figure 6: Meg's timeline showing the best time for Meg to visit the dentist with Tom.

\section{Summary}

All the families visited by DHSWs in this feasibility study lived in socioeconomically deprived areas of Scotland. All participants were mothers with young children, who needed extra support from the DHSWs. Each of the five families had different concerns and needs that acted as barriers and prevented them for attending for dental care. Jane described herself as depressed, Norah had issues related to caring for a child with learning difficulties, Sally suffered from dental anxiety, Mary had a chaotic schedule and although Meg did not express any obvious concerns, she had missed her sons last few dental appointments. Articulation of concerns and parental reflection using CHATTERBOX allowed the DHSW to offer support tailored to the specific needs of each family. Jane's support took the form of practical assistance with watching over her children at the dentist and Norah and Sally benefitted from the relationship they built with their DHSW, which empowered them to keep their children's dental appointments. Conversely, Meg and Mary's needs were poorly communicated and attempts to visit them again to build on previous discussion was unsuccessful.

\section{Discussion}

This qualitative observation illustrated that parents' concerns covered a wide range of issues, ranging from matters that were relatively easy to support such as managing multiple children in the dentist's waiting room, to issues that were less straightforward to address such as parental dental anxiety. Regardless of the actual parental concerns or problems, having a communication platform to talk about their lives and concerns, helped most of these socially excluded mothers find a 'secure base' [27] from which there were able to access dental care for their child. In the words of one of the DHSWs:

".. the family that we used CHATTERBOX with, she had failed so many times and when we got involved she sort of built up a trust and it's like she didn't want to let you down. She has made all her appointments so far. ...they are more likely to attend [long term] if they trust you"

Creating a visual representation of their day, DHSWs' felt, allowed the mothers to reflect on how they organised their days. The following is illustrative: 
"I found that it really helped my mum. She was like 'how come I've got all this free time here but my time here is completely slammed and I'm running about'. I thought it was quite a good tool for parents to think"

Visual health promotion aids such picture books, picture cards and flipcharts have been successfully used by lay health workers, most often to promote healthy behaviours through communication and reinforcing information [28]. The importance of communication in health care has been demonstrated repeatedly. Open and clear communication not only allows for the appropriate tailoring of care, but is also the cornerstone to building good relationships between patients and health care providers, which we know is hugely influential in ensuring adherence $[5,29,30]$. In addition, being able to identify one's own problems and find one's own solution fosters self-efficacy which could lead to sustained behaviour change [31,32], such as regular dental attendance for family and child.

Although CHATTERBOX was developed primarily to provide parents with a platform to voice their concerns around accessing dental care for their children, it also provides an opportunity for children to take part in the discussion around dental attendance, as seen in the example of Family 2. This example illustrates how CHATTERBOX rather than increasing unspoken fears, enabled a discussion of the child's dental anxiety and ultimately facilitated the family's dental attendance.

Although CHATTERBOX proved to be successful in its aim, two factors were identified as potentially limiting its use. The first was getting in touch and maintaining contact with socio-economically deprived families. DHSWs spoke of their constant struggle to maintain contact as families moved around and changed telephone numbers. Moreover, the DHSWs felt that some families they encountered were suspicious of 'support workers' and so pretended to be out to avoid them. It may be proposed that the complexity of Mary's and Meg's individual circumstances intruded into their wish to engage with their DHSW. A single visit was therefore not enough to overcome their fears and reservations, to build an open, trusting relationship. We propose that it is of central importance to encourage and facilitate joint working between the various agencies working with marginalized families. This will allow the DHSWs to provide much needed support, giving sufficient time to parents and the opportunity to build a trusting relationship.

The second limiting factor is linked to the DHSWs' engagement with marginalised families and CHATTERBOX. Engagement or participant responsiveness is an important moderator of programme outcomes, as low levels of engagement can have a detrimental impact on implementation of any health care intervention [33]. Various factors influence the engagement of health care workers with any health intervention [34]. These factors were explored in depth through interviews and focus groups with Childsmile staff [35]. It emerged that organizational (e.g. staff shortages) and individual factors affected how capable and motivated the DHSWs felt about using CHATTERBOX when visiting socially excluded families in their homes.

The problem of accessing families in their homes can be addressed by engaging families with CHATTERBOX in other locations such as, community gatherings like religious groups or parent toddler groups. This approach has its own limitations as families most in need are also least likely to attend such groups and these surroundings may not provide the privacy necessary for such discussions. Nevertheless, CHATTERBOX is a powerful tool that can be adapted or redesigned and used in a variety of settings to engage with people for whom accessing health care is problematic. This is of central importance to reduce health inequalities and foster partnership working across disciplines. For example, it can be developed for use with families with special care needs or in schools, with teachers, to engage with children. It is a tool that has the potential to foster client empowerment through effective communication, raising client critical consciousness and facilitating empowered client-professional relationships; factors essential for individuals and communities to make positive changes in their lives [36].

\section{Conclusions}

This initial exploration of the CHATTERBOX communication intervention indicated that it had the potential to increase engagement and partnership working between marginalised families and DHSWs, to enable dental attendance. Parents liked CHATTERBOX and were willing to ventilate their concerns about their lives and its impact upon dental attendance. On the DHSWs' part, they were able to tailor their support according to the specific concerns identified by the parent and assist them to formulate a solution to enable them to access dental care for their children.

\section{Acknowledgement}

We would like to acknowledge the Childsmile programme (award number: 121.804490) who funded this study. Stephanie Chambers for conducting Phase I and Phase II of the DAPER study. Stephanie Fulke, Rebecca Lindsay and Hazel White, Duncan of Jordanstone College of Art and Design, for designing and producing CHATTERBOX . Childsmile staff at NHS Tayside and NHS Highland and the families who took part in this project, we are indebted to them.

\section{Declaration of Interests}

The authors declare no potential conflicts of interest with regard to publication of this article.

\section{Funding}

The Childsmile Programme [award number: 121.804490].

\section{References}

1. Pinto RZ, Ferreira ML, Oliveira VC, Franco MR, Adams R, et al. (2012) Patient-centred communication is associated with positive therapeutic alliance: a systematic review. Journal of Physiotherapy 58: 77-87.

2. Zolnierek KB, Dimatteo MR (2009) Physician communication and patient adherence to treatment: a meta-analysis. Med Care 47: 826-834.

3. Wanyonyi KL, Themessl-Huber M, Humphris G, Freeman R (2011) A systematic review and meta-analysis of face-to-face communication of tailored health messages: Implications for practice. Patient Education and Counseling 85: 348-355.

4. Martin DJ, Garske JP, Davis MK (2000) Relation of the therapeutic alliance with outcome and other variables: a meta-analytic review. Journal of Consulting And Clinical Psychology 68: 438-450.

5. Nanjappa S, Chambers S, Marcenes W, Richards D, Freeman R (2014) A theory led narrative review of one-to-one health interventions: the influence of attachment style and client-provider relationship on client adherence. Health Education Research 29: 740-754.

6. Griggs J, Walker R (2008) The costs of child poverty for individuals and society. A literature review. Joseph Rowntree Foundation, York. 
Citation: Nanjappa S and Freeman R (2014) CHATTERBOX: Developing and Piloting an Interactive Communication Toolkit for Engaging Families with Dental Services. J Nurs Care 3: 215. doi:10.4172/2167-1168.1000215

Page 7 of 7

7. McPherson R, Tamang J, Hodgins S, Pathak L, Silwal R, et al. (2010) Process evaluation of a community-based intervention promoting multiple maternal and neonatal care practices in rural Nepal. BMC Pregnancy and Childbirth 10: 31.

8. Zimmermann C, Del Piccolo L, Bensing J, Bergvik S, De Haes H, et al. (2011) Coding patient emotional cues and concerns in medical consultations: the Verona coding definitions of emotional sequences (VR-CoDES). Patient Education Counselling 82: 141-148.

9. Del Piccolo L, de Haes H, Heaven C, Jansen J, Verheul W, et al. (2011) Development of the Verona coding definitions of emotional sequences to code health providers' responses (VR-CoDES-P) to patient cues and concerns. Patient Education Counselling 82: 149-155.

10. Locker D (1988) Measuring oral health: a conceptual framework Community Dental Health 5: 3-18.

11. Marcenes W, Kassebaum NJ, Bernabe E, Flaxman A, Naghavi M, et al. (2013) Global burden of oral conditions in 1990-2010: a systematic analysis. Journal of Dental Research 92: 592-597.

12. Sheiham A, James WP (2014) A reappraisal of the quantitative relationship between sugar intake and dental caries: the need for new criteria for developing goals for sugar intake. BMC Public Health 14: 863.

13. Marinho VC, Higgins JP, Sheiham A, Logan S (2003) Fluoride toothpastes for preventing dental caries in children and adolescents. Cochrane Database of Systematic Reviews: CD002278.

14. Levine R (2004) The scientific basis of oral health education. Community Dental Health 21: 131-133.

15. McGrath C, Bedi R (2001) Can dental attendance improve quality of life? Br Dent J 190: 262-265.

16. Pienihakkinen K, Jokela J, Alanen P (2005) Risk-based early prevention in comparison with routine prevention of dental caries: a 7-year followup of a controlled clinical trial; clinical and economic aspects. BMC Oral Health 5: 2 .

17. Savage MF, Lee JY, Kotch JB, Vann WF, Jr. (2004) Early preventive dental visits: effects on subsequent utilization and costs. Pediatrics 114: e418-423.

18. ChildsmileProgramme (Website).

19. Marmot M (2010) Fair society, healthy lives: the Marmot Review: strategic review of health inequalities in England post-2010. London.

20. Macpherson LMD, Ball G, Conway DI, Edwards M, Goold S, et al. (2012) Report of the 2012 detailed National Dental Inspection Programme of Primary 1 children and the basic inspection of Primary 1 and Primary 7 children. Information Services Division, NHS National Services Scotland.

21. Merrett MCW, Goold S, Jones CM, McCall DR, Macpherson LMD, et al. (2009) National Dental Inspection Programme of Scotland: Report of the 2008 Survey of P1 Children. The Scottish Dental Epidemiology Coordinating Committee, Dundee. ISBN : 978-0-9550957-4-0

22. Scottish Executive (2005) An Action Plan for Improving Oral Health and Modernising NHS Dental Services in Scotland. Edinburgh.
23. Information Services Division (2014) Dental Statistics: NHS Registration and Participation. Update of statistics as at 31st March 2014. A National Statistics Publication for Scotland. Information Services Division, NHS National Services Scotland.

24. Chambers SA, Freeman R (2010) Developing an inventory to Assess Parental concerns and Enable child dental Registration. Year 1 report: A qualitative exploration. Dental Health Services Research Unit, University of Dundee.

25. Peter C, Paul D, Sally M, Susan M, Irwin N, et al. (2008) Developing and evaluating complex interventions: the new Medical Research Council guidance. BMJ 337.

26. Truong KN, Hayes GR, Abowd GD (2006) Storyboarding: an empirical determination of best practices and effective guidelines. In: Carroll JM, Bødker S, Coughlin J, editors. Conference on Designing Interactive Systems: ACM. pp. 12-21.

27. Bowlby J (1988) A Secure Base: Clinical Applications of Attachment Theory. London Routledge.

28. Glenton C, Colvin CJ, Carlsen B, Swartz A, Lewin S, et al. (2013) Barriers and facilitators to the implementation of lay health worker programmes to improve access to maternal and child health: qualitative evidence synthesis. Cochrane Database Systematic Reviews 10: CD010414.

29. Griffin SJ, Kinmonth AL, Veltman MW, Gillard S, Grant J, et al. (2004) Effect on health-related outcomes of interventions to alter the interaction between patients and practitioners: a systematic review of trials. Annals of Family Medicine 2: 595-608.

30. Kaplan SH, Greenfield S, Ware JE, Jr. (1989) Assessing the effects of physician-patient interactions on the outcomes of chronic disease. Medical Care 27: S110-127.

31. Rollnick S, Kinnersley P, Stott N (1993) Methods of helping patients with behaviour change. BMJ 307: 188-190.

32. Britt E, Hudson SM, Blampied NM (2004) Motivational interviewing in health settings: a review. Patient Education and Counseling 53: 147-155.

33. Carroll C, Patterson M, Wood S, Booth A, Rick J, et al. (2007) A conceptual framework for implementation fidelity. Implementation Science 2: 40.

34. Cane J, O'Connor D, Michie S (2012) Validation of the theoretical domains framework for use in behaviour change and implementation research. Implementation Science 7: 37.

35. Nanjappa S, Freeman R (2013) Developing an inventory to Assess Parental concerns and Enable child dental Registration. Phase 3 report: Field trial of the PDCS using the Chatterbox intervention Dental Health Services Research Unit, University of Dundee.

36. Laverack G (2005) Public Health: power, empowerment and professional practice. Palgrave Macmillan, Hampshire, New York. 